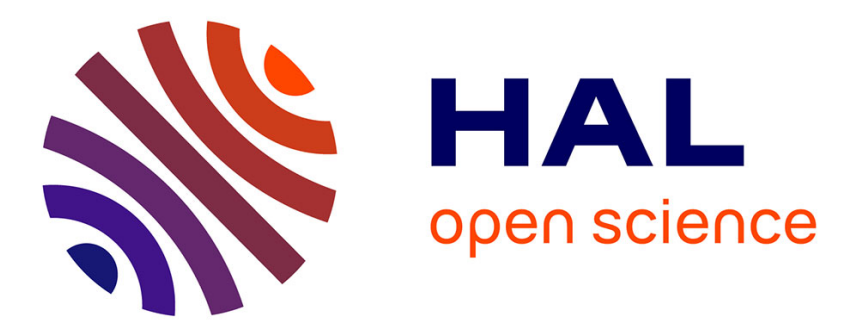

\title{
Structural investigations of the $\mathrm{xTeO}-(1-\mathrm{x}) \mathrm{GeO}(\mathrm{x}=0$, $0.2,0.4,0.6,0.8$ and 1$)$ tellurite glasses: A composition dependent Raman spectroscopic study
}

\author{
A.G. Kalampounias, N.K. Nasikas, G.N. Papatheodorou
}

\section{- To cite this version:}

A.G. Kalampounias, N.K. Nasikas, G.N. Papatheodorou. Structural investigations of the xTeO-(1$\mathrm{x}) \mathrm{GeO}(\mathrm{x}=0,0.2,0.4,0.6,0.8$ and 1$)$ tellurite glasses: A composition dependent Raman spectroscopic study. Journal of Physics and Chemistry of Solids, 2011, 72 (9), pp.1052. 10.1016/j.jpcs.2011.05.016 . hal-00778410

\author{
HAL Id: hal-00778410 \\ https://hal.science/hal-00778410
}

Submitted on 20 Jan 2013

HAL is a multi-disciplinary open access archive for the deposit and dissemination of scientific research documents, whether they are published or not. The documents may come from teaching and research institutions in France or abroad, or from public or private research centers.
L'archive ouverte pluridisciplinaire HAL, est destinée au dépôt et à la diffusion de documents scientifiques de niveau recherche, publiés ou non, émanant des établissements d'enseignement et de recherche français ou étrangers, des laboratoires publics ou privés. 


\section{Author's Accepted Manuscript}

Structural investigations of the $\mathrm{xTeO}_{2}-(1-\mathrm{x}) \mathrm{GeO}_{2}$ $(\mathrm{x}=0,0.2,0.4,0.6,0.8$ and 1$)$ tellurite glasses: $\mathrm{A}$ composition dependent Raman spectroscopic study

A.G. Kalampounias, N.K. Nasikas, G.N. Papatheodorou

PII:

S0022-3697(11)00153-3

DOI:

doi:10.1016/j.jpcs.2011.05.016

Reference: PCS 6473

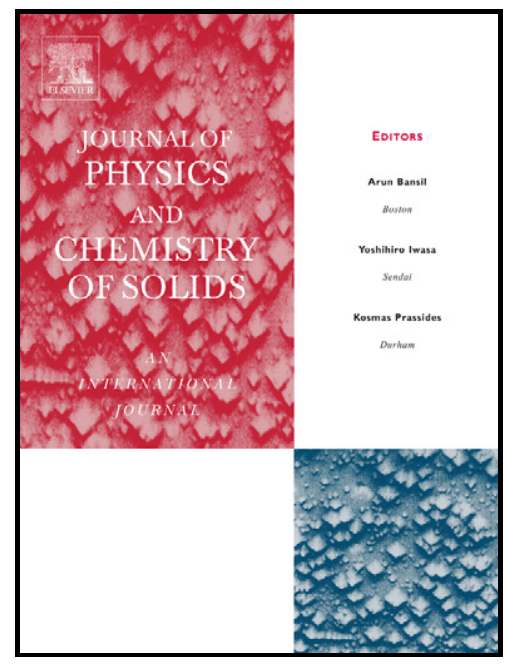

www.elsevier.com/locate/jpcs

To appear in: $\quad$ Journal of Physics and Chemistry of Solids

Received date: $\quad 19$ October 2010

Revised date: $\quad 3$ May 2011

Accepted date: 31 May 2011

Cite this article as: A.G. Kalampounias, N.K. Nasikas and G.N. Papatheodorou, Structural investigations of the $\mathrm{xTeO}_{2}-(1-\mathrm{x}) \mathrm{GeO}_{2}(\mathrm{x}=0,0.2,0.4,0.6,0.8$ and 1) tellurite glasses: $\mathrm{A}$ composition dependent Raman spectroscopic study, Journal of Physics and Chemistry of Solids, doi:10.1016/j.jpcs.2011.05.016

This is a PDF file of an unedited manuscript that has been accepted for publication. As a service to our customers we are providing this early version of the manuscript. The manuscript will undergo copyediting, typesetting, and review of the resulting galley proof before it is published in its final citable form. Please note that during the production process errors may be discovered which could affect the content, and all legal disclaimers that apply to the journal pertain. 
Submitted to J. Phys. Chem. Solids

October 19, 2010

Structural investigations of the $\mathrm{xTeO}_{2}-(1-\mathrm{x}) \mathrm{GeO}_{2}(\mathrm{x}=0,0.2,0.4,0.6,0.8$ and 1$)$

tellurite glasses: A composition dependent Raman spectroscopic study

\author{
A. G. Kalampounias ${ }^{1,2, *}$, N. K. Nasikas ${ }^{1,3}$ and G. N. Papatheodorou, ${ }^{1}$ \\ ${ }^{1}$ Foundation for Research and Technology Hellas - Institute of Chemical Engineering and High \\ Temperature Chemical Processes, FORTH/ICE-HT, P.O. Box 1414, GR - 26 504, Patras, \\ Greece \\ 2 Department of Chemical Engineering, University of Patras, GR - 26 504, Patras, Greece \\ ${ }^{3}$ Department of Materials Science, University of Patras, GR - 26 504, Patras, Greece
}

\begin{abstract}
Raman spectra of $\mathrm{xTeO}_{2}-(1-\mathrm{x}) \mathrm{GeO}_{2}(\mathrm{x}=0,0.2,0.4,0.6,0.8$ and 1$)$ germanium tellurite glasses were measured and analyzed in an effort to follow the structural changes caused by mixing two typical glass-formers. Systematic Raman intensity measurements have been performed in an effort to elucidate the composition induced structural changes and a possible mechanism that accounting for these changes was proposed. The network structure of the glass is characterized by $\mathrm{TeO}_{4}$ trigonal bipyramid mixed with $\mathrm{TeO}_{3}$ trigonal pyramid units, while $\mathrm{GeO}_{4}$ tetrahedral units are also present. Changing the $\mathrm{GeO}_{2}$ content results to conversion of the $\mathrm{TeO}_{4}$ units to $\mathrm{TeO}_{3}$ units with a neutral doubly-bridged oxygen atom, while the existence of charged terminal oxygen atoms is questionable. The measured relative Raman intensities are semi quantitatively correlated to the transformation of the $\mathrm{TeO}_{4}$ trigonal bipyramid into $\mathrm{TeO}_{3}$ trigonal pyramids.
\end{abstract}

Keywords: A. amorphous materials, A. glasses, A. non-crystalline materials, A. oxides, C. Raman spectroscopy

\footnotetext{
* Corresponding author. Department of Chemical Engineering, University of Patras \& Foundation for Research and Technology Hellas - Institute of Chemical Engineering and High Temperature Chemical Processes, P.O. Box 1414, GR-26504 Patras, Greece. Tel.: +30 2610969 558; fax: +30 2610997849 ; e-mail: angelos@chemeng.upatras.gr
} 


\section{Introduction}

Tellurite glasses have scientific and technological interest due to their attractive physical properties such as low melting points, high dielectric constant [1, 2], high refractive index [2] and good infrared transmissivity [3]. The refractive indices allow the utilization of these glasses for non-linear optical materials [4] and the phonon energies have at least two important consequences, the improved infrared transmission up to $6 \mu \mathrm{m}$ and the low multiphonon decay rates compared to other network oxide glasses. Furthermore, tellurite glasses possess chemical durability and are water resistive [5].

Currently, there exist a large amount of literature regarding the structure of pure $\mathrm{TeO}_{2}$ and $\mathrm{xM}_{2} \mathrm{O}-(1-\mathrm{x}) \mathrm{TeO}_{2}\left(\mathrm{M}_{2} \mathrm{O}\right.$ : alkali oxide, $\mathrm{x}$ : mole fraction) glasses with a variety of techniques such as X-ray diffraction [6-8], neutron diffraction [8, 9], NMR [10-12], Mösbauer spectroscopy [13], EXAFS [14], ab initio quantum-mechanical calculations [15, 16], molecular orbital calculations [9], Brillouin [17], IR [ 18, 19] and Raman scattering [20-23]. However, a limited number of papers have been focused on binary glassy systems where both components are glassformers participating directly in the formation of the vitreous network.

For the present work we have prepared the binary glasses $\mathrm{xTeO}_{2}-(1-\mathrm{x}) \mathrm{GeO}_{2}(\mathrm{x}=0,0.2$, $0.4,0.6,0.8$ and 1 ) and study them at room temperature by vibrational Raman spectroscopy. The data are discussed in terms of the glass structure, while emphasis has been given in the local environment around Te and Ge atoms and the effect of composition variation on the structure. 


\section{Experimental}

The reagent grade chemicals Tellurium (IV) oxide (99.99\% purity) and Germanium (IV) oxide $(99.95 \%$ purity) were purchased from Alfa Aesar. The appropriate amounts of polycrystalline $\mathrm{TeO}_{2}$ and glass powder $\mathrm{GeO}_{2}$ were mixed and melted in platinum crucibles at $700-800^{\circ} \mathrm{C}$ for $15-30 \mathrm{~min}$. The homogenized bubble-free liquids were quenched using the conventional method by dipping the crucible into cold water. Heating of the samples was performed at temperatures near the glass transition temperature in order to avoid cracking due to relieve internal stresses generated by quenching.

Raman measurements were obtained using a high-resolution UV-Visible Labram HR800 spectrograph (JY, ISAHoriba group) excited with the $441.8 \mathrm{~nm}$ line of an air-cooled $\mathrm{HeCd}$ laser of Kimmon Electric Co. (Dual, 325/442 nm, UV/blue, 20/80 mW; IK5651R-G model laser). All room temperature spectra were recorder in a backscattering geometry under a microscope where the excitation laser beam was focused onto the sample by a microscope objective $(50 \times / 0.55)$. Spectral slit widths (resolution) were set equal to $2 \mathrm{~cm}^{-1}$, while the scattered light was detected by a CCD detector. Both polarized (VV: vertical polarization of incident laser - vertical analysis of scattered light) and depolarized (VH: vertical polarization of incident laser - horizontal analysis of scattered light) scattering geometries were employed for glasses. A calibration procedure with the aid of a $\mathrm{CCl}_{4}$ sample was often taking place in order to check the polarization and correct for possible drifts of the monochromator's gratings. Accumulation times were adjusted to result in a very high signal-to-noise ratio. 


\section{Results and Discussion}

Room temperature polarized (VV) and depolarized (VH) Raman spectra were measured for germanium tellurite glasses $\mathrm{xTeO}_{2}-(1-\mathrm{x}) \mathrm{GeO}_{2}$ with $\mathrm{x}=0,0.2,0.4,0.6,0.8$ and 1 . The spectra of the "end "glasses and their polarization characteristics were found to be the same as reported before [24, 25]. Fig. 1 shows the polarized Raman spectra of the systems studied in the reduced representation. The benefits of using the reduced representation in analyzing the spectra has been discussed elsewhere [26]. Systematic and gradual intensity and frequency changes of the main bands are observed with composition indicating continuous and overlapping structural modifications of the participating glass formers.

Gaussian analysis of the spectra was performed using the nonlinear regression method based on the Levenberg-Marquardt algorithm. The major component bands correspond to unresolved peak maxima and slope changes in the experimental polarized and depolarized spectra in all fits. This constrains the minimum number of major component bands, their positions and widths, thus involving only few free fitting parameters. A representative example of the deconvolution procedure is shown in the bottom of Fig. 1, where the complete fit of the pure $\mathrm{TeO}_{2}$ spectrum is shown. Four Gaussian profiles are shown in the high-frequency spectral envelop (500-850 $\mathrm{cm}^{-1}$ ) of $\mathrm{TeO}_{2}$ glass. These bands are approximately located at 769, 715, 644 and $583 \mathrm{~cm}^{-1}$ and are marked as D, C, B and A, respectively. In the medium frequency range [400 $\left.-500 \mathrm{~cm}^{-1}\right]$ one Gaussian profile, located at $457 \mathrm{~cm}^{-1}$, can be resolved under the broad spectral envelop of the glass. Below $400 \mathrm{~cm}^{-1}$, a set of at least three broad bands at $\sim 353, \sim 294$ and $\sim 162 \mathrm{~cm}^{-1}$ is required to fit the glass spectra.

It has been proposed that the $\mathrm{TeO}_{2}$ glass is mainly composed of $\mathrm{TeO}_{4}$ trigonal bipyramid units (tbp) and of $\mathrm{TeO}_{3}$ trigonal pyramid units (tp) (see Fig. 2(a) and 2(b)). In $\mathrm{TeO}_{4}$ (tbp) units, 
one equatorial site of the $s p^{3} d$ hybrid orbitals is occupied by a lone pair of electrons and the other two equatorial and axial sites are occupied by oxygen atoms. $\mathrm{In} \mathrm{TeO}_{3}$ (tp) units, one of the $\mathrm{Te} s p^{3}$ hybrid orbitals is occupied by a lone pair of electrons [27]. Ab initio molecular orbital calculations have shown that the stretching motion of the doubly bonded oxygen in the $\mathrm{TeO}_{2 / 2}=\mathrm{O}$ tp unit is expected at $\sim 868 \mathrm{~cm}^{-1}[16]$. In the tbp units, most of the tellurium atoms are connected at vertices by $\mathrm{Te}-$ equatorial $\mathrm{O}_{\text {axial }}-\mathrm{Te}$, linkage, which connects two distinct tbp units, having the oxygen atom in equatorial (short bond distance) for the first and in axial site (long bond distance) for the second tbp unit, respectively [28]. Thus, $\mathrm{TeO}_{2}$ glass has a unique structure owing to these units and its connecting style considerable differs from the conventional glass formers, such as $\mathrm{B}_{2} \mathrm{O}_{3}, \mathrm{SiO}_{2}, \mathrm{GeO}_{2}$ and $\mathrm{P}_{2} \mathrm{O}_{5}$. This would infer that $\mathrm{TeO}_{2}$ may have a structural role differing than that of other conventional oxides in binary glasses which contain network modifiers. Many authors have proposed, based on Raman spectroscopic results, that the primary structural unit of tellurite glasses having high $\mathrm{TeO}_{2}$ content is a distorted $\mathrm{TeO}_{4}$ tbp and that the fraction of $\mathrm{TeO}_{3}$ trigonal pyramids (tp) increases with increasing mono- or di-valent cation oxide content and/or temperature ( see e.g. :[20-23])

The origin of the main bands appearing in the reduced polarized (VV) Raman spectrum of $\mathrm{TeO}_{2}$ glass according to the deconvolution process (bottom of Fig. 3) are tentatively assigned as follows. The bands at $\sim 769$ (D) and $\sim 715 \mathrm{~cm}^{-1}$ (C) have been assigned to stretching modes of $\mathrm{TeO}_{3}$ tp units. The doublet at $\sim 644$ (B) and $\sim 583 \mathrm{~cm}^{-1}$ (A) has been assigned to the stretching modes of the $\mathrm{TeO}_{4}$ tbp units. The two different peaks are presumably related to the two nonequivalent oxygen atoms (those at the equatorial plane and those out of the plane). Further, the broad peak at $\sim 457$ is assigned to $\mathrm{Te}-\mathrm{O}-\mathrm{Te}$ and/or $\mathrm{O}-\mathrm{Te}-\mathrm{O}$ linkages [20,21]. The existence of this band indicates the presence of a continuous network consisting of vertex-sharing 
tellurium - oxygen polyhedra. The peaks observed at below $330 \mathrm{~cm}^{-1}$ in the low-frequency region are assigned to a bending vibration of $\mathrm{TeO}_{3}$ tp having or not charged terminal oxygen atoms $[20,21]$

With increasing the $\mathrm{GeO}_{2}$ content, the $457 \mathrm{~cm}^{-1}$ band of tellurite network merges with the $420 \mathrm{~cm}^{-1}$ band of pure $\mathrm{GeO}_{2}$, which is assigned to the symmetric stretching of bridging oxygen atoms (Ge-O-Ge) in 6-membered $\mathrm{GeO}_{4}$ rings $[25,29]$. The $\sim 347$ and $\sim 520 \mathrm{~cm}^{-1}$ bands in the $\mathrm{GeO}_{2}$ rich spectra are attributed to $\mathrm{D}_{1}$ and $\mathrm{D}_{2}$ defect modes, respectively. The former band is related to Ge 'deformation' motion within the network, while the latter is related to breathing motion of bridging oxygen atoms in 3 -membered $\mathrm{GeO}_{4}$ rings $[25,29]$. In the $500-620 \mathrm{~cm}^{-1}$ region of pure $\mathrm{GeO}_{2}$ and $\mathrm{GeO}_{2}$ rich compositions, the Ge-O-Ge bending modes are present as shoulder bands at $\sim 556$ and $595 \mathrm{~cm}^{-1}$. These bands are assigned to TO and LO split modes associated with significant $\mathrm{Ge}$ and $\mathrm{O}$ motion, respectively. The high-frequency bands observed at $\sim 860$ and $998 \mathrm{~cm}^{-1}$ are the TO and LO split asymmetric stretching bands of the bridging oxygen atoms (Ge-O-Ge) [29]. The TO mode possibly coexists with the expected stretching motion of the doubly bonded oxygen in the $\mathrm{TeO}_{2 / 2}=\mathrm{O}$ tp unit at $\sim 868 \mathrm{~cm}^{-1}$ from ab initio molecular orbital calculations [16]. Due to the strong overlapping of the above reported bands, the population of the doubly bonded oxygen in the $\mathrm{TeO}_{2 / 2}=\mathrm{O}$ tp units cannot be estimated directly from the Raman data.

The deconvolution results of the high-frequency Raman spectra for all compositions are shown in Fig. 3. Apart from the four bands (A - D) attributed to $\mathrm{TeO}_{3}$ tp and $\mathrm{TeO}_{4}$ tbp units, three other bands have been deconvoluted in the higher frequency region of the spectra. These bands are assigned to the asymmetric stretching region of the $v_{3}(F)$ tetrahedral mode of $\mathrm{GeO}_{2}$ in analogy to the pure $\mathrm{SiO}_{2}$ spectrum [30]. Three component modes are expected in the low- 
symmetry distortion fields and indeed three can be resolved in our spectra, which exhibit the same polarization characteristics. Increasing $\mathrm{GeO}_{2}$ content cause an intensification of the Raman peaks in the range $700-790 \mathrm{~cm}^{-1}$ at the expense of the peaks located at lower frequencies implying a gradual transformation from $\mathrm{TeO}_{4}$ tbp to $\mathrm{TeO}_{3}$ tp units. In parallel, a continuous intensity increase of the high-frequency bands appears revealing a strengthening of the germanate network. Furthermore, the frequencies of the A to D bands exhibit an almost linear increase as shown in Fig. 3. The observed blue shift in the frequencies of the peaks attributed to $\mathrm{TeO}_{4}$ tbp and $\mathrm{TeO}_{3}$ tp structural units is probably due to the substitution of $\mathrm{Te}$ atoms in the tellurite network by $\mathrm{Ge}$ atoms with increasing the amount of $\mathrm{GeO}_{2}$ content in the binary system. The substitution of Te atoms by Ge atoms, which possess almost half atomic weight, reduce the "effective mass" leading in tern to blue shift in the vibrational frequencies of the $\mathrm{TeO}_{4}$ tbp and $\mathrm{TeO}_{3}$ tp structural units. The assignment of the blue shift in the Raman spectra to new or mixed structural species is questionable.

In an effort to quantitatively follow the local structure transformation of the $\mathrm{TeO}_{4}$ units into $\mathrm{TeO}_{3}$ units directly from the spectroscopic data, a new procedure was proposed [31]. In this procedure it was assumed that the reduced Raman intensity ratio, $r=\left(I_{r e d}^{V V}(C)+I_{r e d}^{V V}(D)\right) /\left(I_{r e d}^{V V}(A)+I_{r e d}^{V V}(B)\right)$ is proportional to the mole fraction or concentration ratio of $\mathrm{R}=\left[" \mathrm{TeO}_{3}\right.$ "] $/\left[\right.$ " $\mathrm{TeO}_{4}$ "], then the systematics of the structural changes occurring can be examined on the basis of the relation between $\mathrm{R}$ and composition variation. In view of the lack of any other information, we tacitly assume here that the Raman cross-sections of the symmetric stretching modes of these two units are comparable. Figure 5 shows the intensity ratio of the deconvoluted Raman peaks versus $\mathrm{GeO}_{2}$ content. There is an almost linear dependence of the 
intensity ratio on the composition. These results suggest that the conversion of the $\mathrm{TeO}_{4}$ tbp units to $\mathrm{TeO}_{3}$ tp units is enhanced by increasing the $\mathrm{Ge} / \mathrm{Te}$ ratio on the glass matrix.

Since the present glasses are formed by two network formers, it is expected that, unlike alkali tellurite glasses, a few $\mathrm{Te}^{-} \mathrm{O}^{-}$and $\mathrm{Ge}^{-} \mathrm{O}^{-}$charged terminal bonds exist in $\mathrm{GeO}_{2}-\mathrm{TeO}_{2}$ glasses. No vibrations due to charged $\mathrm{Te}^{-\mathrm{O}^{-}}$and $\mathrm{Ge}^{-} \mathrm{O}^{-}$bonds are observed in the Raman spectra of these glasses. In alkali tellurite glasses, charged $\mathrm{Te}^{-\mathrm{O}^{-}}$stretching vibration is observed in the frequency range $700-800 \mathrm{~cm}^{-1}[27 \mathrm{a}]$, while for charged $\mathrm{Ge}-\mathrm{O}^{-}$these vibrations appear above $1000 \mathrm{~cm}^{-1}$ [29]. These vibrations are missing in our spectra. With increasing the $\mathrm{GeO}_{2}$ content, a decrease of the intensities of $\mathrm{A}$ and $\mathrm{B}$ bands accompanied by a parallel increase of the $\mathrm{C}$ and $\mathrm{D}$ bands takes place (Fig.1). Bands A and B are related to the fraction of Te atoms forming $\mathrm{TeO}_{4}$ tbp's, while $\mathrm{C}$ and $\mathrm{D}$ bands correspond to $\mathrm{Te}$ atoms forming $\mathrm{TeO}_{3}$ tp units. This suggests that a part of $\mathrm{TeO}_{4}$ tbp polyhedra change into $\mathrm{TeO}_{3}$ tp units with increasing the $\mathrm{GeO}_{2}$ content. In alkali tellurite glasses the conversion of $\mathrm{TeO}_{4}$ to $\mathrm{TeO}_{3}$ is induced by the addition of high basicity oxygen accompanied with alkali oxide or alkaline earth oxide, which act as network modifiers The $\mathrm{GeO}_{2}$ is a known representative glass former but, it seems that in the case of $\mathrm{GeO}_{2}-\mathrm{TeO}_{2}$ glasses the $\mathrm{GeO}_{2}$ acts like a network modifier that causes cleavage of Te-O-Te linkages and steps up the conversion of $\mathrm{TeO}_{4}$ to $\mathrm{TeO}_{3}$ units. Such conversion is presumably less effective in comparison with the $\mathrm{TeO}_{4}$ to $\mathrm{TeO}_{3}$ conversion caused by the alkali tellurite network modifiers.

A schematic representation of the overall structure is shown in Fig. 2 (c), where $\mathrm{GeO}_{4}$ tetrahedral units are interconnected via common oxygen atoms to trigonal bipyramidal and trigonal pyramidal units. The amount of $\mathrm{TeO}_{3}$ (tp) units depends on the $\mathrm{GeO}_{2}$ content. The stretching Te-O frequency of trigonal bipyramidal $\mathrm{TeO}_{3 / 2} \mathrm{O}^{-}$and trigonal pyramidal $\mathrm{TeO}_{1 / 2} \mathrm{O}^{-}=O$ units with charged terminal bonds is expected to appear in the $800-1000 \mathrm{~cm}^{-1}$ 
frequency range. The absence of these bands in our spectra even for high $\mathrm{GeO}_{2}$ content indicates that the presence of such species is questionable.

\section{Conclusions}

In this paper we present a detailed analysis of the Raman spectra of $\mathrm{xTeO}_{2}-(1-\mathrm{x}) \mathrm{GeO}_{2}(\mathrm{x}$ $=0,0.2,0.4,0.6,0.8$ and 1) germanium tellurite glasses over a broad composition range aiming in elucidation of the structural changes caused by mixing two typical glass-formers. The network structure of the glass is formed by mixing $\mathrm{TeO}_{4}$ trigonal bipyramid and $\mathrm{TeO}_{3}$ trigonal pyramid units. $\mathrm{GeO}_{4}$ tetrahedral units are also present, while the presence of mixed polyhedra is questionable. With increasing the $\mathrm{GeO}_{2}$ content, a gradual conversion of the $\mathrm{TeO}_{4}$ units to $\mathrm{TeO}_{3}$ units with a neutral doubly-bridged oxygen atom takes place with a parallel increase of their vibrational frequencies. No spectral evidence appears for the presence of charged terminal oxygen atoms in the network. Detailed analysis of the reduced Raman spectra made it possible to quantitatively follow the transformation of the $\mathrm{TeO}_{4}$ trigonal bipyramids - that dominates in the $\mathrm{TeO}_{2}$ rich glasses - into $\mathrm{TeO}_{3}$ trigonal pyramids with composition variation and a structural model accounting for the tellurite network was proposed. 


\section{References}

[1] D. R. Ulrich, J. Am. Ceram. Soc. 47 (1964) 595.

[2] J. E. Stanworth, Nature 169 (1952) 581.

[3] H. Burger, W. Vogel, V. Kozhukharov, Infrared Phys. 25 (1985) 395.

[4] K. Shioya, T. Kmatsu, H. G. Kim, R. Sato, K. Matsusita, J. Non-Cryst. Solids 189 (1995) 16.

[5] M. J. Redman, J. H. Chen, J. Am. Ceram. Soc. 50 (1967) 523.

[6] G. W. Brady, J. Chem. Phys. 27 (1) (1957) 300.

[7] Y. Dimitriev, J. C. J. Bart, V. Dimitrov, M. Z. Arnaudov, Z. Anorg. Allg. Chem. 479 (1981) 229.

[8] J. C. McLaughlin, S. L. Tagg, J. W. Zwanziger, J. Phys. Chem. B, 105 (2001) 67.

[9] H. Niida, T. Uchino, J. Jin, S.-H. Kim, T. Fukunaga, T. Yoko, J. Chem. Phys. 114 (1) (2001) 459 .

[10] S. Sakida, S. Hayakawa, T. Yoko. J. Non-Cryst. Solids 243 (1999) 1.

[11] S. Sakida, S. Hayakawa, T. Yoko. J. Non-Cryst. Solids 243 (1999) 13.

[12] J. C. McLaughlin, S. L. Tagg, J. W. Zwanziger, D. R. Haeffner, S. D. Shastri, J. NonCryst. Solids 274 (2000) 1 .

[13] T. Nishida, M. Yamada, H. Ide, Y. Ikushima, J. Mater. Sci. 25 (1990) 3546.

[14] A. Osaka, Q. Jianrong, T. Nanba, J. Takada, Y. Miura, T. Yao, J. Non-Cryst. Solids 142 (1992) 81 .

[15] O. Noguera, M. Smirnov, A. P. Mirgorodsky, T. Merle-Mejean, P. Thomas, J.-C. Champarnaud-Mesjard, J. Non-Cryst. Solids 345-346 (2004) 734.

[16] T. Uchino, T. Yoko, J. Non-Cryst. Solids 204 (1996) 243. 
[17] M. Ahart, T. Yagi, Y. Takagi, Physica B, 219-20 (1996) 550.[18] N. Mochida, K. Takahashi, K. Nakata, S. Shibusawa, J. Ceram. Soc. Jpn, 86 (7) (1978) 316.

[19] M. Dimitrova-Patkova, Y. Dimitriev, M. Arnaudov, V. Dimitrov, Phys. Chem. Glasses $30(6)(1989) 260$.

[20] T. Sekiya, N. Mochida, A. Ohtsuka, M. Tonokawa, J. Non-Cryst. Solids 144 (1992) 128.

[21] M. Tatsumisago, T. Minami, Y. Kowada, H. Adashi, Phys. Chem. Glasses 35 (2) (1994) 89; A. G. Kalampounias, G. N. Papatheodorou, S. N. Yannopoulos, J. Phys. Chem. Solids, 67 (2006) 725.

[22] M. Tatsumisago, S.-K. Lee, T. Minami, Y. Kowada, J. Non-Cryst. Solids 177 (1994) 154; A. G. Kalampounias, S. N. Yannopoulos, G. N. Papatheodorou, J. Phys. Chem. Solids, 68 (2007) 1035.

[23] O. Noguera, T. Merle-Mejean, A. P. Mirgorodsky, M. B. Smirov, P. Thomas, J.-C. Champarnaud-Mesjard, J. Non-Cryst. Solids 330 (2003) 50; A. P. Mirgorodsky, T. Merle-Mejean, J.-C. Champarnaud, P. Thomas, B. Frit, J. Phys. Chem. Solids 61 (2000) 501.

[24] T. Sekiya, N. Mochida, A. Ohtsuka, M. Tonokawa, J. Ceram. Soc. Jpn. Inter. Ed. 97 (1989) 1440.

[25] F. L. Galeener, J. Non-Cryst. Solids, 40 (1980) 527.

[26] G. N. Papatheodorou and S. N. Yannopoulos, in Molten Salts:From Fundamentals to Applications, edited by M. Gaune-Escard (Kluwer Academic, Dordrecht, 2002), pp. 47106.

[27] T. Sekiya, N. Mochida, A. Ohtsuka, M. Tonokawa, J. Non-Cryst. Solids 144 (1992 ) 128;

M. Tatsumisago, T. Minami, Y. Kowada, H. Adashi, Phys. Chem. Glasses 35 (1994) 89; 
O. Noguera, T. Merle-Mejean, A. P. Mirgorodsky, M. B. Smirov, P. Thomas, J-C Champarnaud-Mesjard, J. Non-Cryst. Solids 330 (2003) 50.

[28] T. Sekiya, N. Mochida, A. Ohtsuka, M. Tonokawa, J. Ceram. Soc. Jpn. 97 (1989) 1440.

[29] L. Giacomazzi, P. Umari, A. Pasquarello, Phys. Rev. Lett., 95 (2005) 075505; G. S. Henderson, G. M. Bancroft, M. E. Fleet, D. J. Rogers, Am. Minerals, 70 (1985) 946; G. S. Henderson, M. E. Fleet, J. Non-Cryst. Solids, 134 (1991) 259; M. Micoulaut, L. Cormier, G. S. Henderson, J. Phys.: Condens. Matter 18 (2006) R753.

[30] A. G. Kalampounias, S. N. Yannopoulos, G. N. Papatheodorou, J. Chem. Phys., 124 (2006) 014504.

[31] A. G. Kalampounias, G. N. Papatheodorou, S. N. Yannopoulos, J. Phys. Chem. Solids, 68 (2007) 1029. 


\section{Figure captions}

\section{Fig. 1}

Reduced polarized (VV) Raman spectra of $\mathrm{xTeO}_{2}-(1-\mathrm{x}) \mathrm{GeO}_{2}(\mathrm{x}=0,0.2,0.4,0.6,0.8$ and 1) glasses at room temperature. Fitting example is shown only for pure $\mathrm{TeO}_{2}$ glass. Open circles: experimental data (only $33 \%$ of the experimental points are shown for clarity). Thick solid line: total fit curve. Gaussian lines: individual vibrational peaks. The various components are described in the text.

\section{Fig. 2}

Schematic model of the structure of $\mathrm{xTeO}_{2}-(1-\mathrm{x}) \mathrm{GeO}_{2}$ glasses. The addition of $\mathrm{GeO}_{2}$ into the $\mathrm{TeO}_{4 / 2}$ network leads to the formation of $\mathrm{TeO}_{3}$ tp with neutral terminal bonds $\left(\mathrm{TeO}_{2 / 2}=\mathrm{O}\right)$. The basic structural unit in the binary tellurite glasses is the $\mathrm{TeO}_{4}$ tbp in $\mathrm{TeO}_{2}$-rich glasses, while $\mathrm{GeO}_{4 / 2}$ tetrahedral units are present with increasing the amount of $\mathrm{GeO}_{2}$.

Notation: tbp=trigonal bipyramids and $\mathrm{t} p=$ trigonal pyramid.

Fig. 3

Deconvoluted polarized (VV) Raman spectra of $\mathrm{xTeO}_{2}-(1-\mathrm{x}) \mathrm{GeO}_{2}(\mathrm{x}=0,0.2,0.4,0.6,0.8$ and 1) glasses at room temperature. Open circles: experimental data (only $33 \%$ of the experimental points are shown for clarity). Thick solid lines: total fit curve. Gaussian lines: individual vibrational peaks. 


\section{Fig. 4}

Compositional dependence of the frequencies of deconvoluted peaks observed in polarized (VV) Raman spectra of $\mathrm{xTeO}_{2}-(1-\mathrm{x}) \mathrm{GeO}_{2}(\mathrm{x}=0,0.2,0.4,0.6,0.8$ and 1$)$ glasses at room temperature.

Fig. 5

Stretching modes intensity ratio $r=\left(I_{\text {red }}^{V V}(C)+I_{\text {red }}^{V V}(D)\right) /\left(I_{\text {red }}^{V V}(A)+I_{\text {red }}^{V V}(B)\right)$ vs $\mathrm{GeO}_{2}$ content at ambient temperature. Line is drown as guide to the eye. See text for details concerning the deconvolution procedure. 


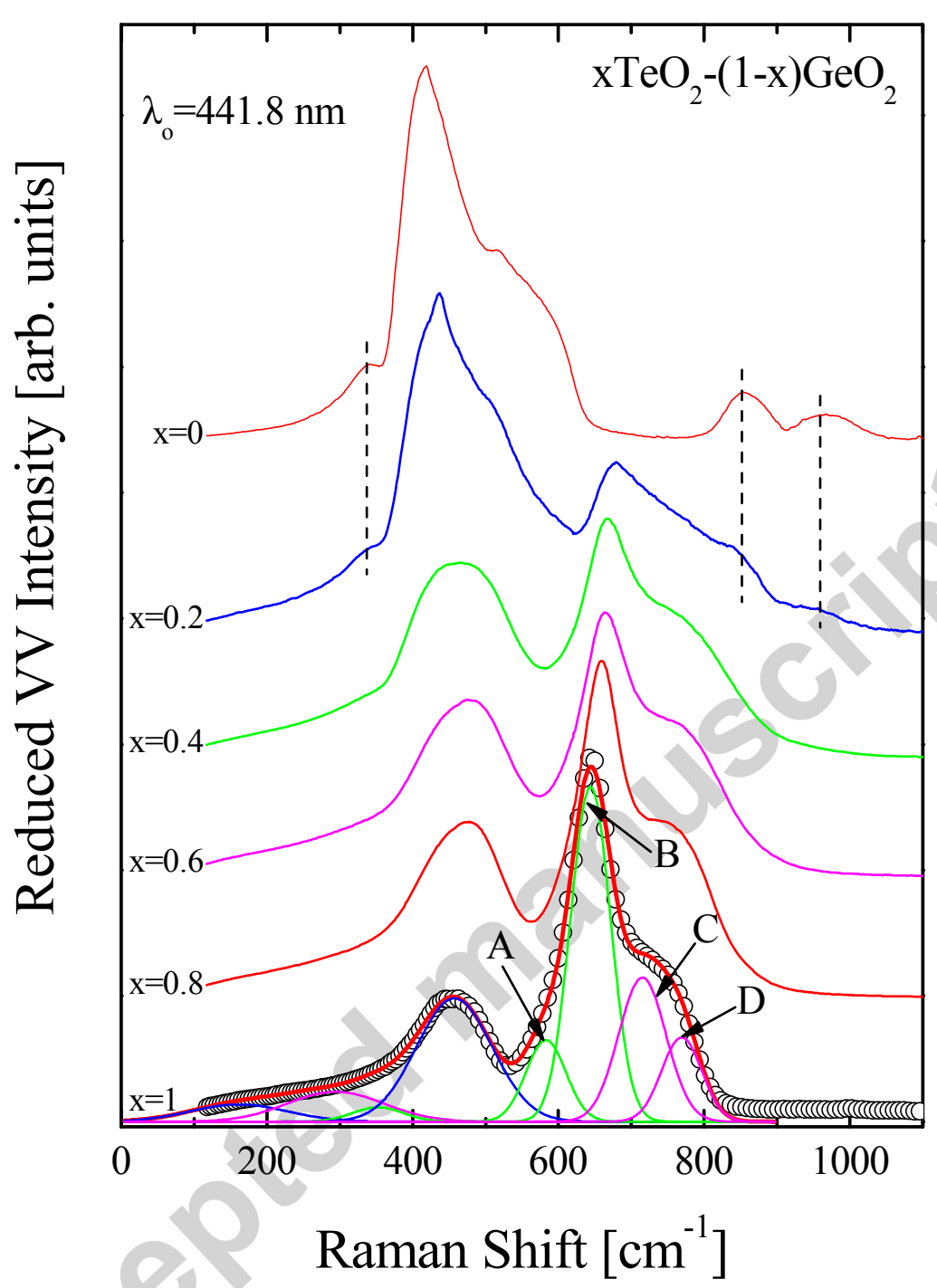

Figure 1 
(a)

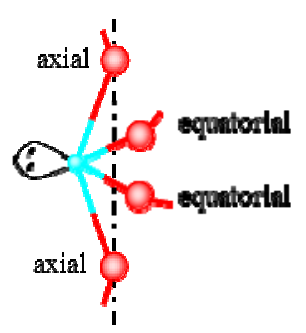

(b)

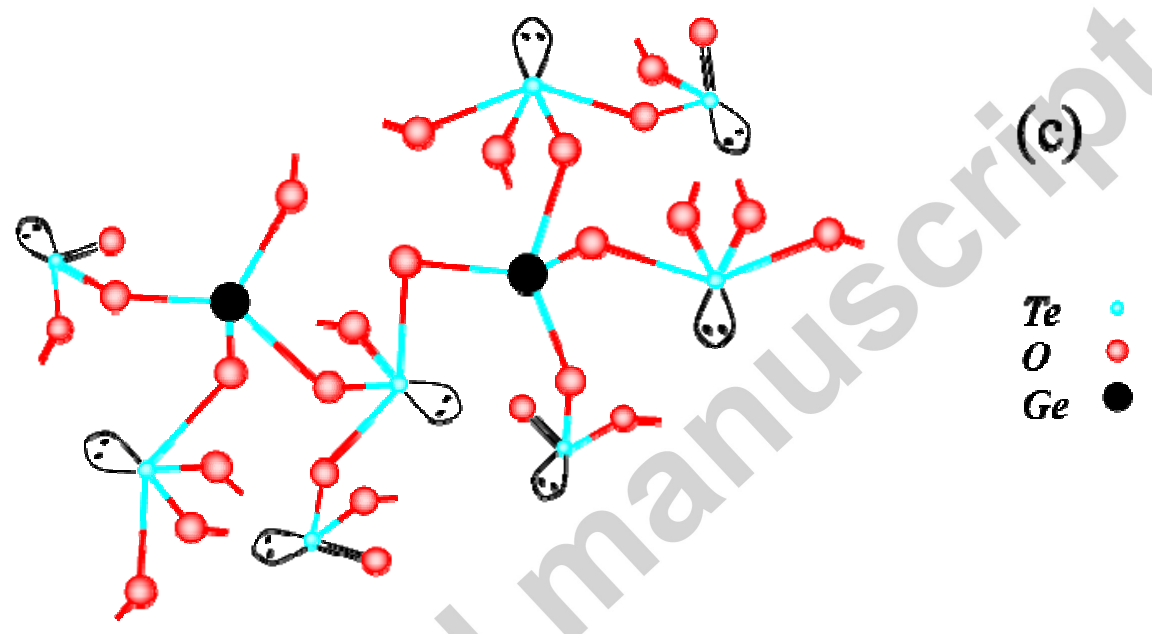

Figure 2 


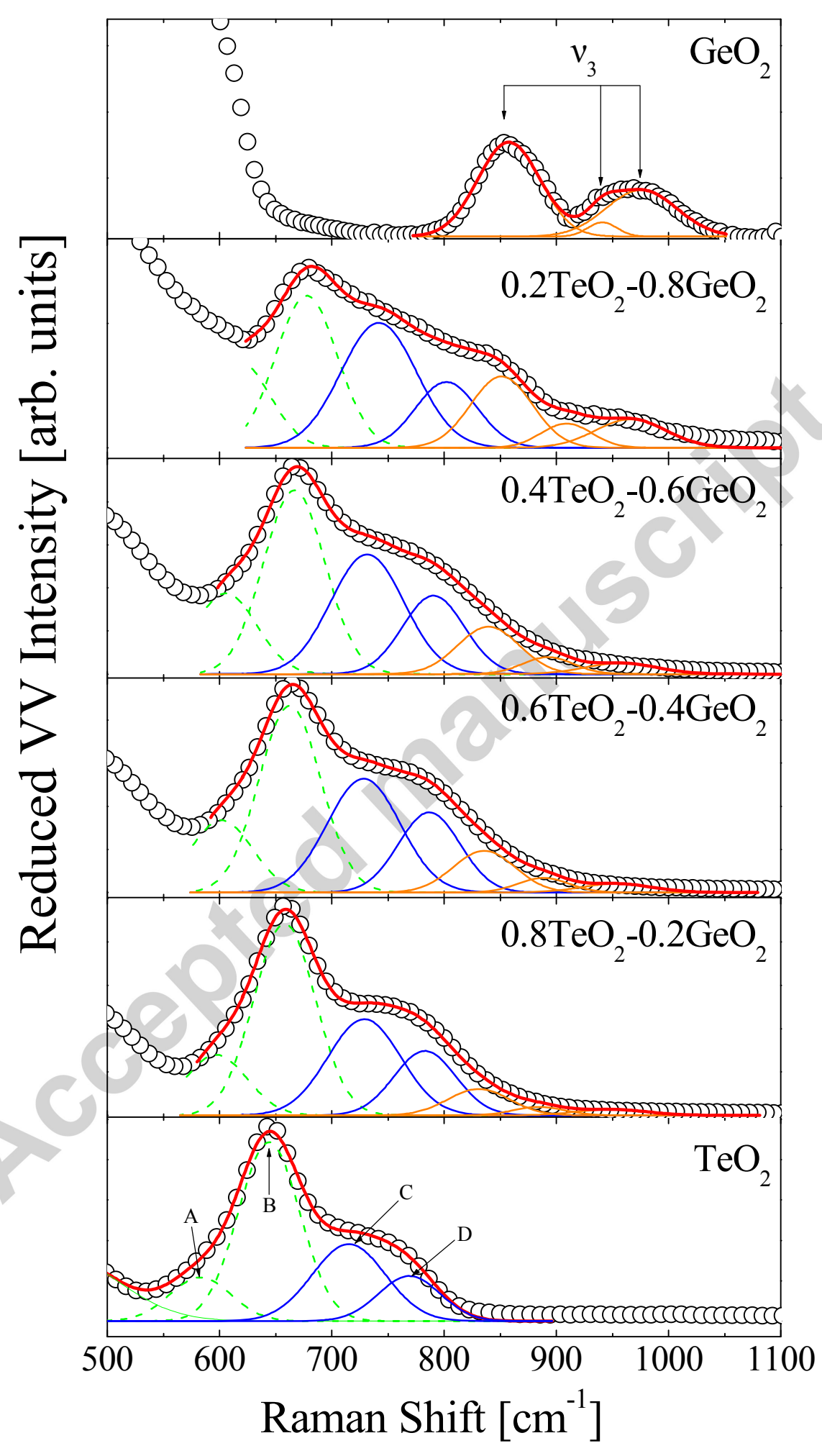

Figure 3 


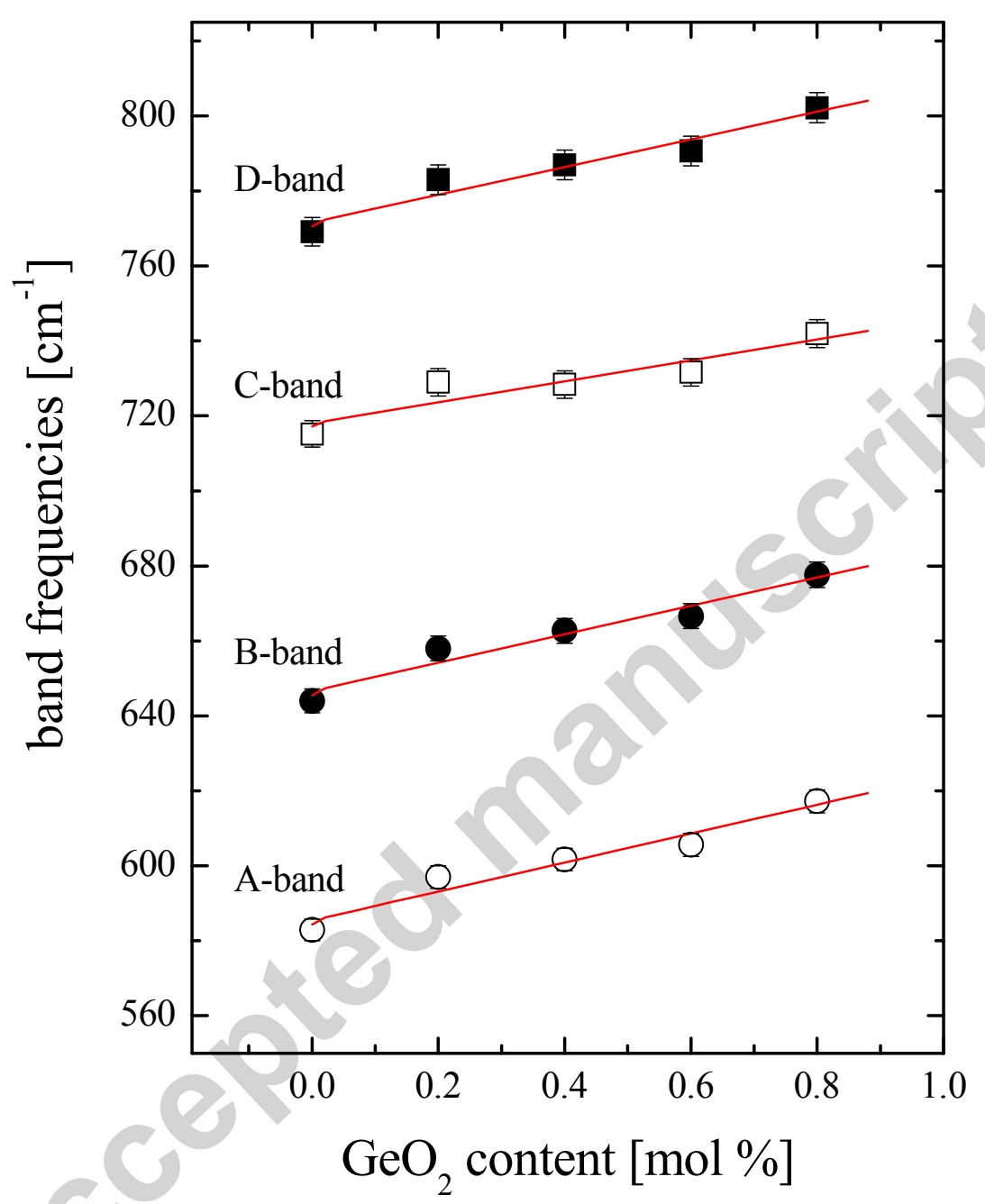

Figure 4 


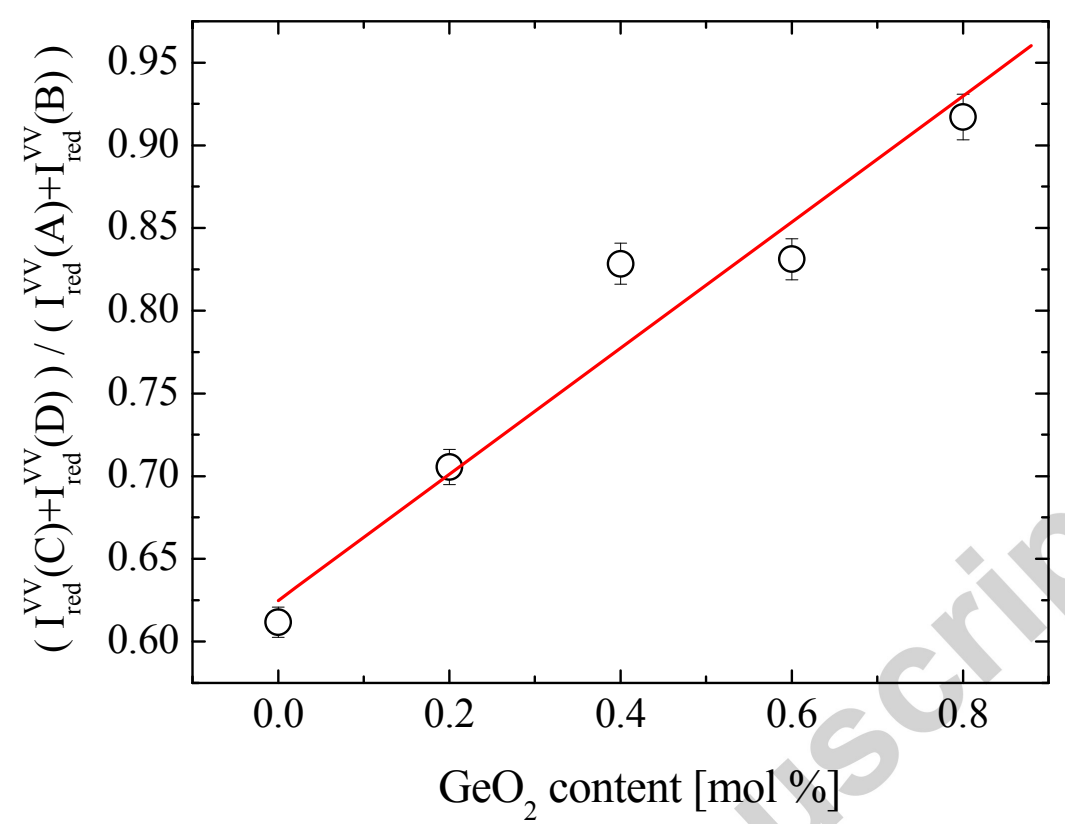

Figure 5 
- Study of binary glasses with both components participating in the vitreous network formation

- Emphasis has been given in the Te and Ge local environment and the composition effect on the structure

- Quantitative estimation of the $\mathrm{TeO}_{4}$ tbp into $\mathrm{TeO}_{3}$ tp transformation with composition variation

- A structural model accounting for the tellurite network is proposed

- Correlation between glass stability and structural alterations 